\title{
A Quantitative Approach to Assess Seismic Vulnerability of Touristic Accommodations: Case Study in Montreal, Canada
}

\author{
Thomas Candela ${ }^{1, *}$, Philippe Rosset ${ }^{2}$ and Luc Chouinard ${ }^{2}$ \\ 1 Department of Geography and Urban Planning, Université Paul-Valéry \& RisCrises BE, \\ 34000 Montpellier, France \\ 2 Department of Civil Engineering, McGill University, Montreal, QC H3A 0C3, Canada; \\ philippe.rosset@affiliate.mcgill.ca (P.R.); luc.chouinard@mcgill.ca (L.C.) \\ * Correspondence: thomas.can@hotmail.fr
}

check for

updates

Citation: Candela, T.; Rosset, P.;

Chouinard, L. A Quantitative

Approach to Assess Seismic

Vulnerability of Touristic

Accommodations: Case Study in

Montreal, Canada. GeoHazards 2021,

2,137-152. https://doi.org/

10.3390 /geohazards2020008

Academic Editor: Tiago

Miguel Ferreira

Received: 17 April 2021

Accepted: 14 June 2021

Published: 16 June 2021

Publisher's Note: MDPI stays neutral with regard to jurisdictional claims in published maps and institutional affiliations.

Copyright: (c) 2021 by the authors. Licensee MDPI, Basel, Switzerland. This article is an open access article distributed under the terms and conditions of the Creative Commons Attribution (CC BY) license (https:/ / creativecommons.org/licenses/by/ $4.0 /)$.

\begin{abstract}
In many places of the world, the interruption of touristic activities in the aftermath of a catastrophic earthquake is often neglected in the evaluation of seismic risks; however, these activities can account for a significant proportion of short-term and long-term economic impacts for these regions. In the last decade, several rapid visual screening techniques have been developed to define the typology of buildings and to estimate their seismic vulnerability and potential for damage. We adapted the existing screening procedures that have been developed for generic buildings to specific circumstances that are most common for tourist accommodations. The proposed approach considered six criteria related to structural and nonstructural elements of buildings, as well as local soil conditions. A score was assigned to each criterion as a function of the capacity of the elements to resist ground shaking. A vulnerability index in four levels of building vulnerability was developed combining the scores of the six criteria. The approach was tested in a pilot area of Montreal to a set of 70 typical buildings grouped in four categories based on their accommodation capacity. In Montreal, tourism is an important source of income for the city where 351,000 room-nights were booked with total stay expenditures of CAD 4.9 billion in 2019. The results indicated potential significant disruptions in activities related to tourism; $46 \%$ of the buildings investigated have a high to very high vulnerability index. Among them, 4/5 are located in the old city and 1/5 in the downtown area of the pilot zone.
\end{abstract}

Keywords: earthquake; building vulnerability; vulnerability index; touristic economy; Montreal

\section{Introduction}

The medium- to long-term impact of damaging earthquakes on the tourist industry is often neglected when quantifying economic losses as if mid- to long-term effects can be considerable. Mazzocchi and Montini [1] reported a 40\% reduction in tourist expenditures in the ten-month period following the M5.9 Umbria Marche earthquake with respect to the estimated expenditure in the same period under normal conditions. Yang et al. [2] estimated a period of three years to recover the tourism incomes after the Wenchuan earthquake (M8.0, May 12, 2008). In Japan, the tourist industry suffered a drop in activities and even a complete shutdown of some facilities for several months after the 2011 Tohoku earthquake [3].

The vulnerability analysis of the tourist sector to different natural disasters has already been investigated by various authors (e.g., [4,5]) but still represents a small part of research in the field of natural risk management [6]. For example, the 2017 hurricanes that have caused severe damage to touristic infrastructures in the Caribbean highlighted the need to strengthen the resilience of this industry [7], to better understand the potential impacts of natural disasters on structures [8], and to consider the cascading effects of the communication breakdown [9]. Orchiston [10] evaluated the consequences of the 2011 Christchurch M6.3 earthquake in New Zealand on the transportation infrastructures and 
the travel flows of the earthquake after the event. She also quantified the level of preparedness and several resilience factors of the tourism businesses facing an earthquake from a survey of the touristic operators. Dhellemmes [11] used a similar approach to estimate the preparedness of tourist accommodations for earthquake risk in San Francisco. He calculated the losses and potential damage of hotels using the HAZUS software. Rosa [12] analyzed the economic impact of tsunamis on Thailand's tourism after the 2005 M8.6 earthquake. In Sumatra, the effective policies to mitigate losses of its tourist sector help to rapidly recover the revenues, which represent around $6 \%$ of its gross domestic product. They consist of a global reconstruction plan to quickly reopen hotels funded by foreign donors and governments; the private sector played a key role to improve the resilience of guests by introducing certification procedures. A tsunami readiness program for hotels has been developed to provide guidelines for the preparation of operating procedures.

In 1988, the US Federal Emergency Management Agency (FEMA-154) was the first to propose a method for the rapid visual screening (RVS) of buildings that has been improved until their last report in 2015 [13]. RVS is a sidewalk approach that was initially used to evaluate the typology of buildings and their structural and nonstructural elements in order to assign a score to buildings in the investigated area. The score has been further converted to vulnerability categories reflecting the capacity of the building to resist seismic loading. In Canada, the National Research Council (NRC1992) adapted the approach to the Canadian context [14] and included several aspects for the seismic vulnerability assessment of buildings in the National Building Code of Canada (NBCC2005) [15]. In 2012, Alam et al. [16] published a review of six approaches, including the FEMA one, used at the national scale and scored them following three criteria related to the general description of vulnerability, the evaluated physical parameters, and the description of the outputs. They then evaluated the application of the approach in three cities, including one in Canada (Kelowna), and concluded that a hybrid approach combining the FEMA-154 and NRC1992 assessment performed well in the Canadian context. The outputs of these approaches were then used to calculate damage grades for a certain level of ground shaking by using probabilistic approaches, neural networks, machine learning, and fuzzy logic to capture the inherent uncertainties of such an analysis (e.g., Harirchian et al. [17] for an up-to-date review of existing approaches). The RVS has been recently used in Italy for school buildings [18]. We propose in this paper the combination of the FEMA-154 and the NRC1992 procedures to the specificity of the buildings accommodating tourists in Montreal.

In 2019, more than 11.1 million tourists visited Montreal with total expenditures of approximately CAD 4.86 billion [19]. The tourism industry accounts for about 53,000 direct and indirect jobs in the province of Quebec, which is also ranked third for the number of annual international congresses/conferences in North America. More than 351,000 room nights in commercial accommodations have been registered for an average occupation rate of $74 \%$ in 2019. Predicting the potential damage to lodging facilities due to a major earthquake is of interest as tourism losses are ultimately linked to the state of the accommodations. Montreal is located in a moderate seismic zone, as shown in the earthquakes and faults map of Figure 1. The location of the recorded earthquakes since 1980 indicates two main active zones within the Western Quebec Seismic Zone: one band in the NW direction from Montreal, which is the site of three major earthquakes: a magnitude 6 event near Montreal in 1732 [20]; a magnitude 6.1 event near Timiskaming in 1935 [21]; and a magnitude 5.8 event near Cornwall-Massena in 1944 [22]. These earthquakes correlate with a normal faulting zone from the Paleozoic or later periods along the Ottawa River that may represent a failed rift [23]. The second band is oriented SW-NE and extends along the Saint-Lawrence River where several large earthquakes were reported, the most recent being the M5.9, Saguenay earthquake in 1988. Several recent weak earthquakes were felt by many in the urban area of Montreal (black crosses in Figure 1). With respect to population at risk, the city is ranked second in Canada after Vancouver [24]. 


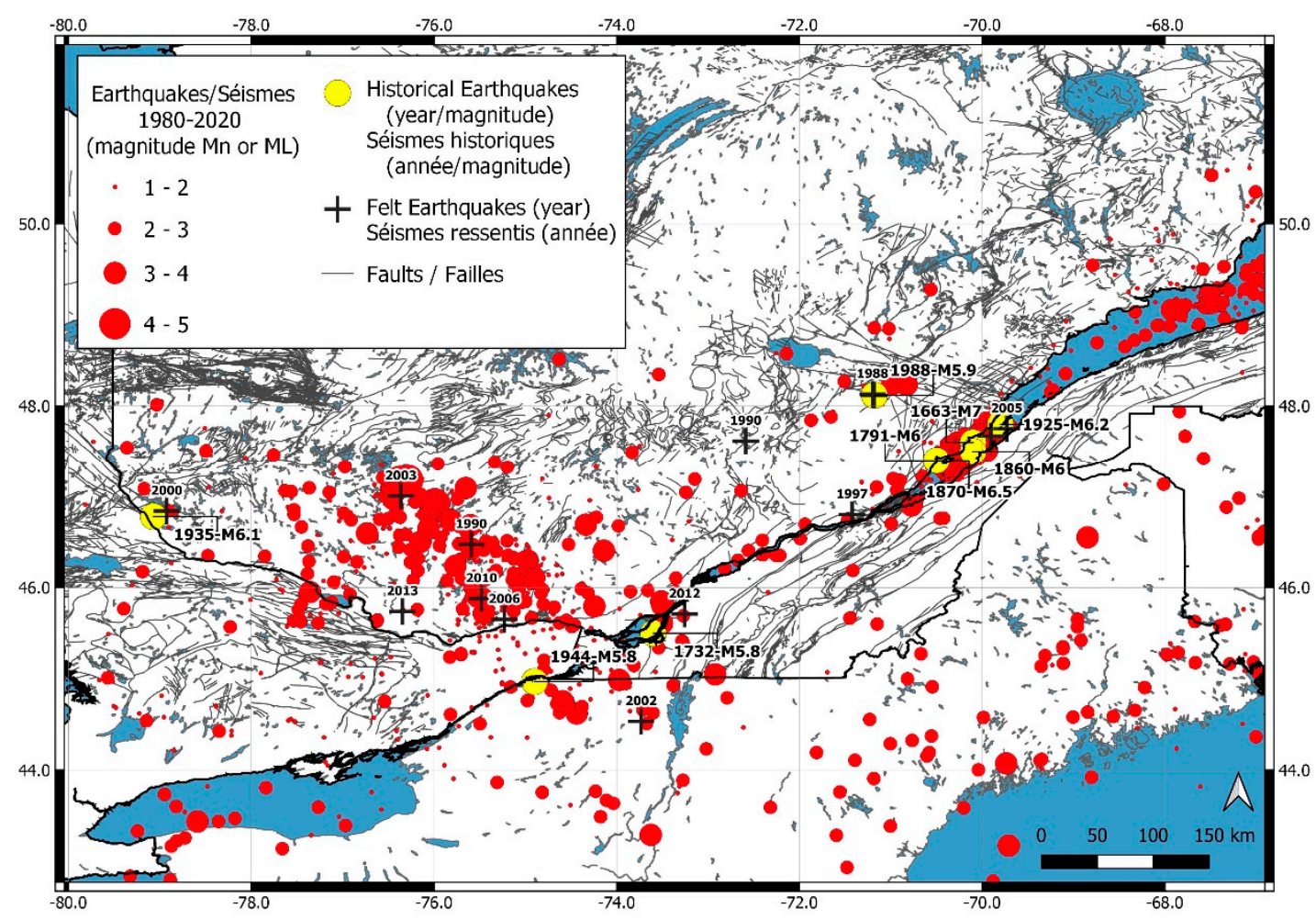

Figure 1. Felt historical and recorded earthquakes around the Greater Montreal area for the period 1663-2020. The earthquakes list is provided by Natural Resources Canada and fault lines from the Ministère de l'Énergie et des Ressources naturelles of the Quebec province and the Ontario Geological Survey.

In addition, recent nonconsolidated deposits have been identified as a contributing factor in amplifying ground motions and damage $[25,26]$. The effect of local amplification was illustrated during the magnitude 5.9 Saguenay earthquake of 1988. Despite an epicentral distance exceeding $300 \mathrm{~km}$, the external masonry wall of the Montreal-East City Hall was extensively damaged due to local amplification associated with a thick layer of marine clay. The advanced state of deterioration of the building might also have been a contributing factor [27]. Except for the 1732 M5.8 earthquake, which destroyed approximately 300 houses, the Montreal area has been affected by relatively weak events. However, recent estimates of seismic hazard and risk studies have shown that Modified Mercalli Intensities (MMIs) of VII and VIII events can be expected in the future [28]. On average, extensive and complete damage could affect approximately $0.5 \%$ of the total building stock and cause casualties (fatalities plus injuries) varying between 350 and 500 depending on the time of the earthquake occurrence [29]. Rosset et al. [30] calculated that the total losses varied between 1 and $12 \%$ of the value of the portfolio for residential houses (2018 value) depending on the selected earthquake scenario.

The impact of a large earthquake (as defined by the seismic hazard provided by Natural Resources Canada for a return period of 2475 years) on the tourist sector in Montreal has yet to be evaluated. In the present paper, a procedure is proposed to assess its vulnerability based on a score matrix considering the vulnerability of both structural and nonstructural components of the building, the economic value of the building, and the local soil conditions that may amplify seismic motions. A set of 70 representative tourist accommodations (from hostels to large hotels) were selected in a pilot zone, including the old city and the recently urbanized downtown area (Figure 2). The results are then discussed from different perspectives. 


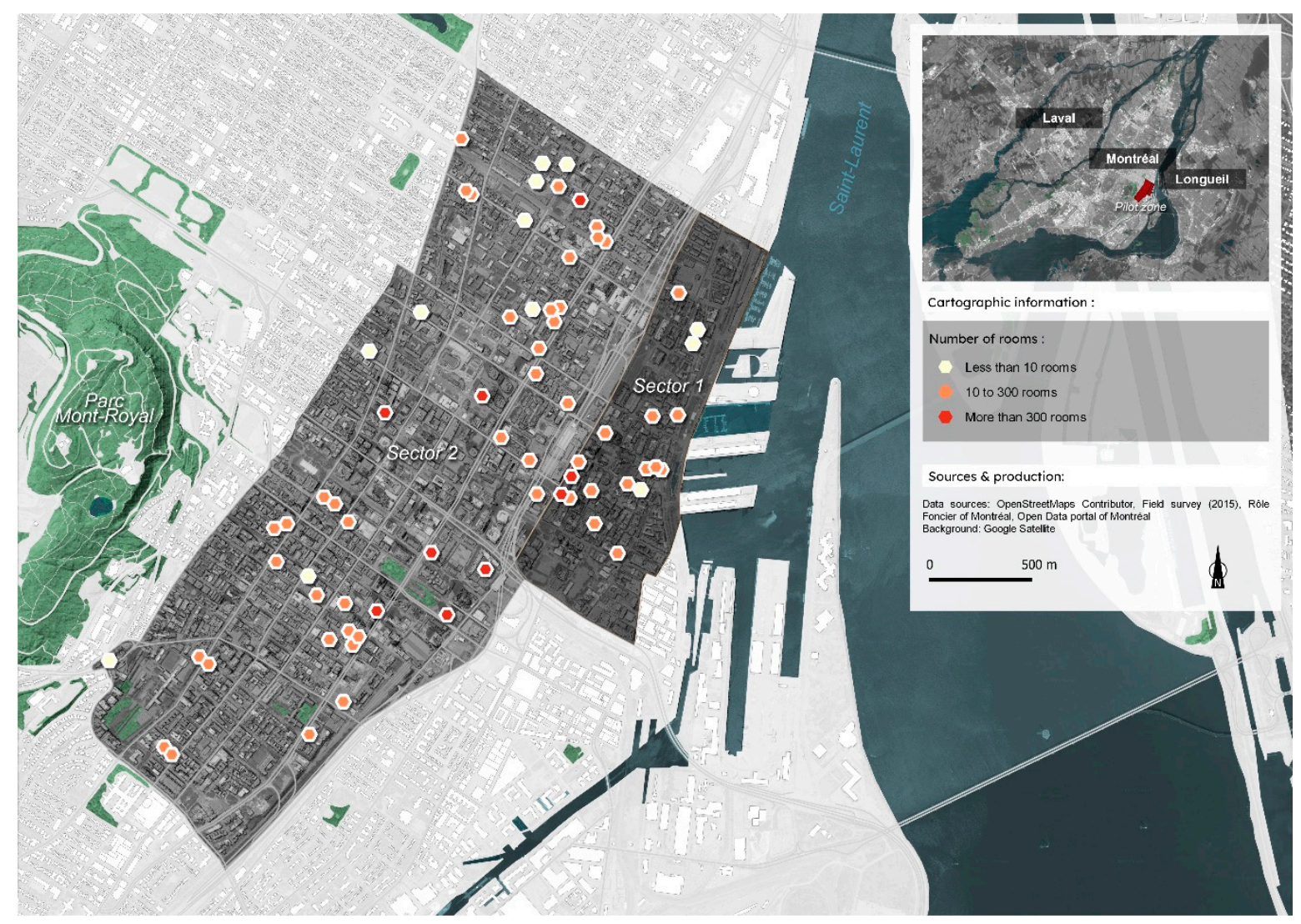

Figure 2. Location of the pilot area divided into two sectors and the investigated touristic accommodations grouped by their number of rooms.

\section{Materials and Methods}

\subsection{The Pilot Study Zone}

The pilot study covered the zone between the old port of Montreal and its downtown, and it was selected because of its representative diversity of tourist accommodations. It was divided into two sectors, as shown in the map of Figure 2: Sector-1, including the old city, represents $10 \%$ of the total capacity of the investigated accommodations with approximately 900 rooms compared to more than 8500 rooms for Sector-2, which is part of downtown. The location and the room capacity of the selected buildings are shown in the map of Figure 2. The old city was first settled in 1642 and is a main tourist attraction with nearly 7 million visitors per year. Buildings are mainly unreinforced masonry, many of which have been converted into hotels or guest houses. It is therefore the most vulnerable zone in the pilot study. Downtown Montreal combines buildings from different periods spanning the 18th century with old masonry structures to modern tall buildings of steel and concrete. This densely urbanized area represents the economic heart of the city and comprises the highest density of hotels in the city.

A total number of 70 hotels were selected in the two sectors among this group, which can be classified in four categories, as illustrated in Figure 3:

1. Bed and breakfasts including lodging houses and youth hostels. These often consist of individual or multiple wood frame dwellings. The hostels are larger than private lodgings, which have 3 to 5 floors.

2. Small hotels. These have less than four floors and a maximum of 30 rooms. They are mostly located in the sector-1 old-port area and were generally built before 1965, predating the first modern building seismic code. The economic value of each building depends on the age of the building, the star rating of the accommodations, and the average occupancy rate. 
3. Intermediate hotels. These have more than 30 rooms and often with a number of floors between 4 and 7 . The construction type is mainly reinforced masonry with construction dates between 1900 and 2010. They are classified as hotels with three to four stars.

4. Large hotels. These are tall buildings with more than 20 floors of steel and concrete frame types.
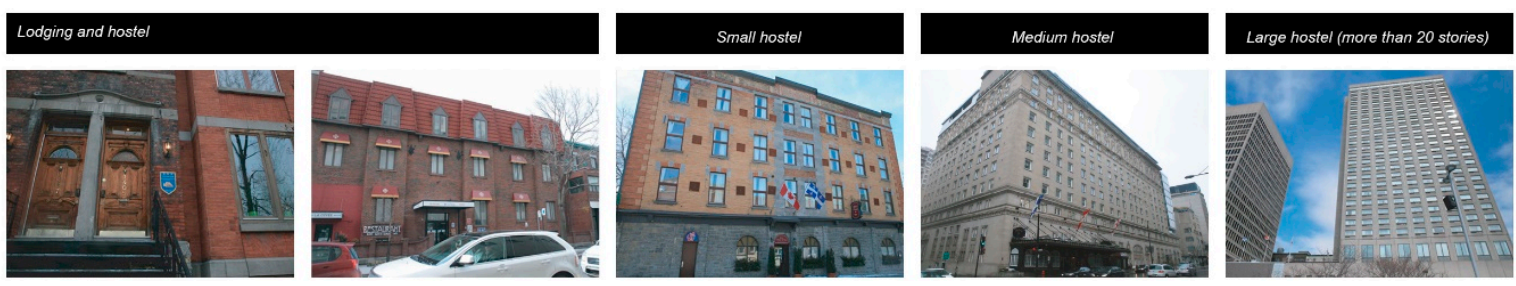

Figure 3. Tourist accommodations grouped in four types: (1) Bed and Breakfast; (2); small hotel (3), intermediate hotel; (4) large hotel.

The number of services provided to customers increases with each category of hotel.

\subsection{Method to Assess the Vulnerability of the Hotel Sector}

The method proposed in this paper integrates the data involving hazard and vulnerability analysis. The seismic hazard at the local scale is based on an existing soil microzonation $[25,26,28-31]$. The vulnerability assessments for masonry buildings are based on the analyses performed by Lefebvre [32]. These were supplemented with the vulnerability study performed by Uma and al. [33] in Christchurch and the evaluation method proposed by Zacek [34]. The method is inspired by the previous RVS procedures from the NBCC2005 [15] using the NRC1992 [14] evaluation grid and from the FEMA-154 [13].

A grid summarizing the main elements of building vulnerability (Table 1) has been prepared in order to score the level of vulnerability. It includes parameters on the structural performance of the building, its architectural form, and other characteristics, as well as the local soil conditions. A flowchart describing the general application of the procedure is shown in the Appendix A.

Table 1. Criteria used to determine the building seismic vulnerability (adapted from NRC1992, NBCC2005, and FEMA-154).

\begin{tabular}{cccccc}
\hline A & B & C & D & E & F \\
\hline $\begin{array}{c}\text { NBCC } \\
\text { design }\end{array}$ & $\begin{array}{c}\text { Type of } \\
\text { structure }\end{array}$ & $\begin{array}{c}\text { Soil } \\
\text { conditions }\end{array}$ & $\begin{array}{c}\text { Building } \\
\text { characteristics }\end{array}$ & $\begin{array}{c}\text { Nonstructural } \\
\text { elements }\end{array}$ & $\begin{array}{c}\text { Importance } \\
\text { elements }\end{array}$ \\
\hline $\begin{array}{c}\text { Age and } \\
\text { resonance } \\
\text { period of the } \\
\text { building }\end{array}$ & $\begin{array}{c}\text { Concrete, } \\
\text { steel, } \\
\text { masonry, etc. }\end{array}$ & $\begin{array}{c}\text { Hard rock, } \\
\text { firm soil, soft } \\
\text { soil }\end{array}$ & $\begin{array}{c}\text { Structural } \\
\text { irregularities, } \\
\text { number of } \\
\text { floors }\end{array}$ & $\begin{array}{c}\text { Fireplace } \\
\text { presence and } \\
\text { balcony. } \\
\text { Induced } \\
\text { hazards }\end{array}$ & $\begin{array}{c}\text { Occupancy } \\
\text { rate and } \\
\text { accommoda- } \\
\text { tion } \\
\text { capacity }\end{array}$ \\
\hline
\end{tabular}

The vulnerability index Vi for a given building is calculated using the following formula:

$$
\mathrm{Vi}=\mathrm{IS}+\mathrm{INS}
$$

where IS is the structural index obtained from the multiplication of the scores for the criteria A, B, C, D, and F related to structural parameters, and INS is the nonstructural index calculated by multiplying the scores for the criteria $\mathrm{C}$, E, and F (Table 1). C and F are criteria used both for IS and INS as structural and nonstructural impacts are influenced by soil conditions and will affect the accommodation capacity. Most of the scores adopted in our method are from NRC1992 and, when needed, are adapted for their application to the 
specificity of the hotel sector in Montreal. Each criterion, as well as the source of the scores, is explained later in the text.

Criterion A is based on the year of construction of the building and its fundamental period of resonance. The year of construction is related to the evolution of the seismic provisions of the building code whose first edition was in 1945. Four periods are defined: before 1965, from 1965 to 1985 corresponding to the first national seismic codes using ground motions from a probabilistic seismic zoning map; from 1985 to 2005 when a point source model seismic zonation was first introduced; and from 2005 onwards [35].

The year of construction of the building was obtained from field surveys that are validated by information from the property assessment roll (later called the roll) for the Montréal agglomeration (Evaluation foncière Montréal, 2015). The period of resonance of the building Ta was calculated using the approximate relation $\mathrm{Ta}$ (in s) $=\mathrm{N} / 10$ for a stiff structure, where $\mathrm{N}$ is the number of storeys. The selected ranges for Ta were adapted to fit the soil resonance given by Chouinard and Rosset [36] as a function of location.

Values for criterion A are given in the matrix of Table 2 and follow the National Building Code of Canada [13]. It varies between 0.7 and 2.3 depending on the resonance period of the building Ta and the year of construction.

Table 2. Matrix used to determine criterion A (adapted from NRC1992, NBCC2005, and FEMA-154).

\begin{tabular}{ccccc}
\hline \multirow{2}{*}{$\begin{array}{c}\text { Ta: Period of the Building (in s) } \\
\text { N: Number of Floors }\end{array}$} & Before 1965 & $\mathbf{1 9 6 5 - 1 9 8 4}$ & $\mathbf{1 9 8 5 - 2 0 0 5}$ & Bfter 2005 \\
\cline { 2 - 5 } $\mathrm{Ta} \leq 1.0 ; \mathrm{N} \leq 10$ & 2.3 & 1.5 & 1.5 & 1 \\
\hline $1.0<\mathrm{Ta}<2.0 ; 10<\mathrm{N}<20$ & 1.3 & 0.9 & 0.9 & 0.7 \\
\hline $\mathrm{Ta} \geq 2.0 ; \mathrm{N} \geq 20$ & 0.9 & 0.7 & 1 \\
\hline
\end{tabular}

Criterion B is obtained by considering simultaneously the built year and its structural type. Buildings are divided into eight structural types, as defined in Table 3. The information is obtained from the roll and visual inspections. The values range from 1 to 4.3 , and the largest values are assigned to structures built before 1965 with masonry or concrete walls. The B value for post- 2005 buildings is set to one and does not influence the IS value.

Table 3. Matrix used to determine criterion B (adapted from NRC1992, NBCC2005, and FEMA-154).

\begin{tabular}{ccccccccc}
\hline & \multicolumn{1}{c}{ Structural Type } \\
\cline { 2 - 10 } Built Year & Wood & Steel & $\begin{array}{c}\text { Steel } \\
\text { Frame }\end{array}$ & Concrete & $\begin{array}{c}\text { Concrete } \\
\text { Frame }\end{array}$ & $\begin{array}{c}\text { Precast } \\
\text { Concrete }\end{array}$ & $\begin{array}{c}\text { Reinforced } \\
\text { Masonry }\end{array}$ & $\begin{array}{c}\text { Unreinforced } \\
\text { Masonry }\end{array}$ \\
\hline Before 1965 & 1.4 & 1 & 2 & 2 & 2.5 & 4.3 & 3.3 & 3.5 \\
\hline $1965-1984$ & 1.4 & 1 & 1.5 & 1.5 & 1.5 & 3.1 & 2.2 & 3.5 \\
\hline $1985-2005$ & 1.2 & 1 & 1 & 1 & 1 & 1.7 & 1 & 1 \\
\hline After 2005 & 1 & 1 & 1 & 1 & 1 & 1 & 1 \\
\hline
\end{tabular}

Criterion C combines the local soil condition of the building and its year of construction. Rosset and Chouinard [26] demonstrated that the amplification on soft soil could be typically larger than 2 for a M6.0 earthquake in Montreal depending on the soil type and thickness of the soft soil layer. The division of soil conditions into five soil categories comes from the NBCC2005 [15]. The factors in the Table 4 were adapted to the soil categories from those given in NRC1992 [14]. For the buildings built after 2005, a factor of 1.5 was adopted to consider the potential of liquefaction in poor soils. 
Table 4. Matrix used to determine criterion C (adapted from NRC1992 and NBCC2005).

\begin{tabular}{cccccc}
\hline \multirow{2}{*}{ Built Year } & \multicolumn{5}{c}{ Soil Categories } \\
\cline { 2 - 6 } & Hard Rock & Rock & Dense Soil & Soft Soil & Poor Soil \\
\hline Before 1965 & 0.8 & 0.9 & 1 & 1.1 & 1.2 \\
\hline $1965-1984$ & 0.8 & 0.9 & 0.8 & 0.8 & 0.9 \\
\hline 1985-2005 & 0.8 & 0.9 & 0.8 & 0.8 & 0.9 \\
\hline After 2005 & 1 & 1 & 1 & 1 & 1.5 \\
\hline
\end{tabular}

Criterion D is first related to structural irregularities of the building, its environment, and level of deterioration (Table 5a). Horizontal and vertical irregularities in the shape of the building are determined from field surveys and satellites images. Interviews with the maintenance staff helped to determine the presence of soft story and short concrete beams in the building when available plans were missing. These are two critical points because they affect the resistance of the building in the case of strong ground motion. The pounding risk mainly depends on the height of adjacent structures and the gap between them. In order to simplify the RVS and Vi calculation, we integrated in our analysis both parameters (height and gap) for this factor, as indicated in the NRC1992 [14]. Finally, the level of deterioration of the building, which decreases its overall resistance, was estimated by visual screening. Here, the year 1985 was selected as a pivotal date in the score definition in accordance with the national building codes evolution in terms of seismic provisions. The adopted scores were relatively similar for these two periods except when the presence of a soft story or important structural modifications were identified. The final value of $\mathrm{D}$ is the sum of the scores for structural irregularities observed in a given building.

Table 5. Matrix used to determine criterion D (adapted from NRC1992 and NBCC2005).

(a)

\begin{tabular}{|c|c|c|c|c|c|c|c|}
\hline \multirow[b]{2}{*}{$\begin{array}{l}\text { Age of the } \\
\text { Building }\end{array}$} & \multicolumn{7}{|c|}{ Structural Irregularities } \\
\hline & $\begin{array}{c}\text { Vertical } \\
\text { Irregularities }\end{array}$ & $\begin{array}{l}\text { Horizontal } \\
\text { Irregularities }\end{array}$ & Soft-Story & Modification & $\begin{array}{c}\text { Short } \\
\text { Concrete } \\
\text { Columns }\end{array}$ & $\begin{array}{l}\text { Pounding } \\
\text { Risk }\end{array}$ & Deterioration \\
\hline Before 1985 & 1.3 & 1.5 & 2 & 1.3 & 1.3 & 1.3 & 1.3 \\
\hline After 1985 & 1.3 & 1.5 & 1.5 & 1 & 1.3 & 1.3 & 1.3 \\
\hline \multicolumn{8}{|c|}{ (b) } \\
\hline \multicolumn{8}{|c|}{ Soil-Structure Interaction } \\
\hline \multirow{2}{*}{\multicolumn{2}{|c|}{$\begin{array}{c}\text { Zones \& } \\
\text { Predominant Period T }\end{array}$}} & \multicolumn{6}{|c|}{ Number of floors \& Building Period Ta (in s) } \\
\hline & & \multicolumn{2}{|c|}{$1-4 \& 0.1-0.4$} & \multicolumn{2}{|c|}{$4-7 \& 0.4-0.7$} & \multicolumn{2}{|c|}{$>7 \&>0.7$} \\
\hline \multicolumn{2}{|c|}{ Zone i $(\mathrm{T} \leq 0.12 \mathrm{~s})$ * } & \multicolumn{2}{|c|}{1.5} & \multicolumn{2}{|c|}{1.1} & \multicolumn{2}{|c|}{1} \\
\hline \multicolumn{2}{|c|}{ Zone ii $(0.12<\mathrm{T}<0.22 \mathrm{~s}) *$} & \multicolumn{2}{|c|}{2} & \multicolumn{2}{|c|}{1.2} & \multicolumn{2}{|c|}{1} \\
\hline \multicolumn{2}{|c|}{ Zone iii $(\mathrm{T} \geq 0.22 \mathrm{~s})$ * } & \multicolumn{2}{|c|}{2} & \multicolumn{2}{|c|}{1.5} & \multicolumn{2}{|c|}{1} \\
\hline
\end{tabular}

* The different zones are located in the map of Figure 4.

The second part of criterion D refers to the soil-structure interaction considering both the predominant period of the building resonance Ta and of the soil $\mathrm{T}$. The latter was provided by the microzonation map from Rosset and Chouinard [26] and grouped in three zones $\mathrm{i}$, ii, and iii, where the limits for T were 0.12 and $0.22 \mathrm{~s}$, respectively, as shown in the map of Figure 4 and listed in the Table $5 \mathrm{~b}$. The resonance period of the building Ta is given approximately by the relation $\mathrm{Ta}(\mathrm{s})=\mathrm{N} / 10$ for stiff structures, where $\mathrm{N}$ is the number of stories. The highest values of $\mathrm{D}$ are given to buildings with 1 to 4 floors, which have periods close to the resonance periods of the soil observed in the pilot zone. 


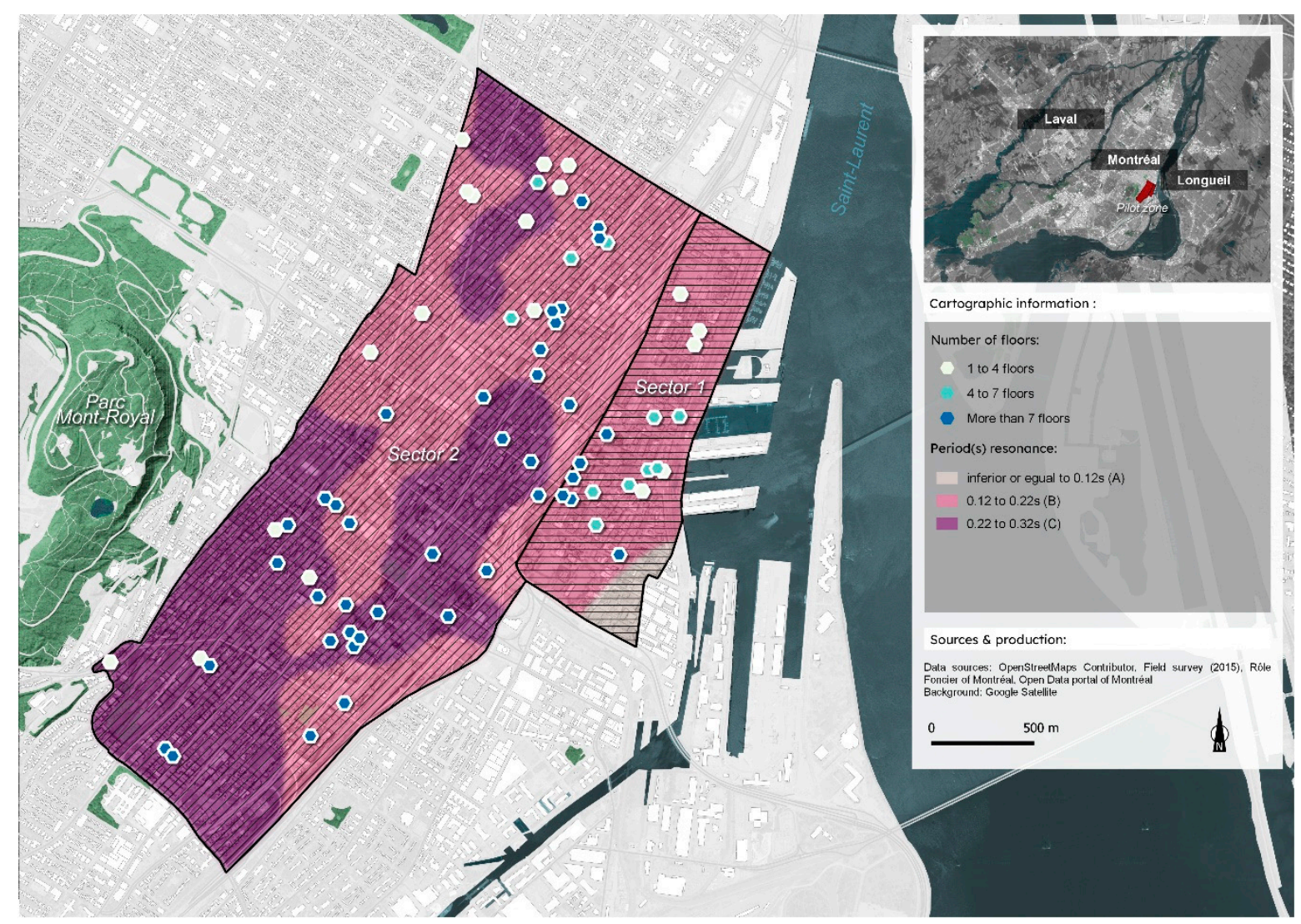

Figure 4. Zonation in terms of the resonance period of the soil T (in s) based on the map from Rosset and Chouinard [23].

Criterion E expresses the vulnerability due to nonstructural elements of the buildings that may pose a threat when falling during the earthquake and a few minutes later as chimneys, firewalls, external walls, or balcony (Table 6).

Table 6. Matrix used to complete criterion E (adapted from FEMA-154).

\begin{tabular}{lcc}
\hline & No & Yes \\
\hline $\begin{array}{l}\text { Presence of nonstructural elements } \\
\text { (i.e., chimney, external wall, balcony) }\end{array}$ & 1 & 2 \\
\hline
\end{tabular}

The last criterion $\mathrm{F}$ quantifies the importance of the hotel based on its overnight occupancy rate and the accommodation capacity (Table 7). The latter combines the average price for a room, the number of rooms, and the average annual occupancy rate, as provided by the manager of the tourist accommodation. Both criteria use three levels of importance with a factor derived from NRC1992 and NBCC2005. The total score is the multiplication of the two sub-scores: frequentation and accommodation capacity, representing the global importance level of the building.

Table 7. Matrix used to determine criterion F (adapted from NRC1992 and NBCC2005).

\begin{tabular}{cccc}
\hline Importance of the Building & Low & Medium & Important \\
\hline $\begin{array}{c}\text { Frequentation } \\
\text { (number of persons } \\
\text { accommodated per night) }\end{array}$ & $\begin{array}{c}1 \\
(0-10)\end{array}$ & $\begin{array}{c}1.2 \\
(10-100)\end{array}$ & $\begin{array}{c}1.5 \\
(100-1000)\end{array}$ \\
\hline $\begin{array}{c}\text { Accommodation capacity } \\
\text { (expressed in CAD) }\end{array}$ & $\begin{array}{c}1.2 \\
(100-5000 \mathrm{k})\end{array}$ & $\begin{array}{c}1.3 \\
(5000-10,000 \mathrm{k})\end{array}$ & $\begin{array}{c}1.5 \\
(>10,000 \mathrm{k})\end{array}$ \\
\hline
\end{tabular}


The scores for structural criteria A, B, C, D, and F were multiplied to calculate the IS value. The INS value was then calculated by multiplication of the scores $C$ and F. Values of the vulnerability index Vi, which is the sum of IS and INS (Equation (1)), were then grouped in four levels of vulnerability from low to very high, as shown in Table 8 . The limit between each level was adapted from the typology found in standard diagnostic analysis [13] and from the distribution of Vi values of the present study, which varied from 10 to 50 .

Table 8. Vulnerability index Vi grouped into four levels of vulnerability.

\begin{tabular}{lcccc}
\hline Vulnerability Index Vi & $<10$ & $10-20$ & $20-30$ & $>30$ \\
\hline Level of vulnerability & Low & Intermediate & High & Very High \\
\hline
\end{tabular}

\section{Results}

\subsection{Estimated Vulnerability index of Hotels in the Pilot Zone}

The value of $\mathrm{Vi}$ was calculated for the 70 different touristic accommodations selected in the pilot zone. The graph in Figure 5 shows the distribution of the vulnerability classes by type. The hostels and lodgings are the types with the worst seismic performance as $89 \%$ of them have a high to very high levels of vulnerability. This value decreases to $65 \%, 24 \%$, and $9 \%$ for small, intermediate, and large hotels, respectively.

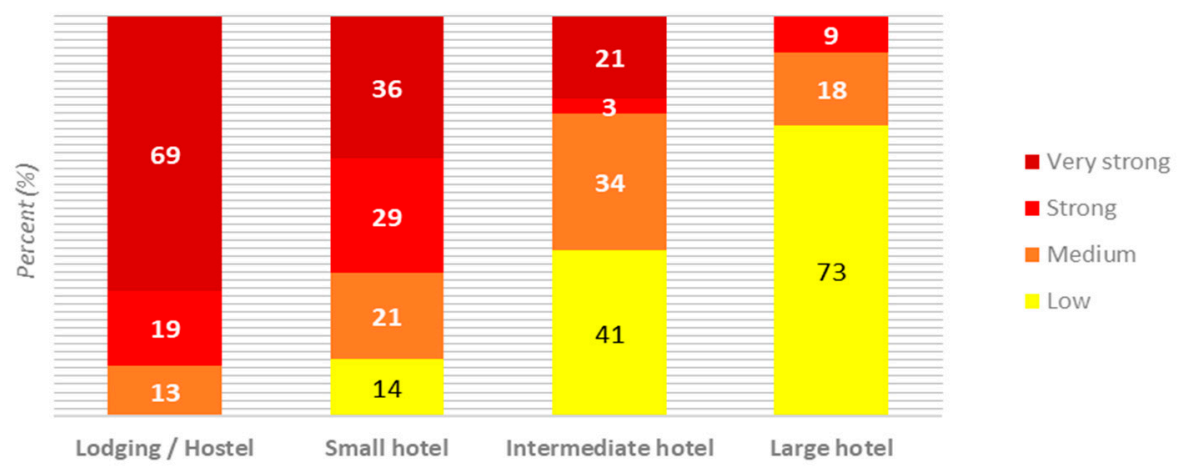

Figure 5. Distribution by vulnerability index Vi for the different accommodation types (in \%).

Table 9 gives the average criteria obtained for the four different types of accommodations and the averaged final score. The very high average level of vulnerability (Vi of 32) for Bed and Breakfasts is explained by their location downtown where unreinforced masonry structures on soft soil are predominant. Small hotels are mainly old reinforced masonry buildings with four floors on average, which are ranked second in terms of vulnerability (Vi of 27). One should notice that the vulnerability of the masonry buildings is different if they have a rigid or flexible diaphragm, a parameter that we did not consider in our analysis, due to lack of information. Intermediate and large hotels are concrete and steel frame buildings with more than 10 floors with an intermediate and low level of vulnerability, respectively. The average score for the overall samples was around 20 at the limit between intermediate and high vulnerability index, as indicated in Table 8. 
Table 9. Average value of criteria for the vulnerability index by types of accommodations.

\begin{tabular}{|c|c|c|c|c|c|}
\hline \multirow{2}{*}{ Criteria } & & \multicolumn{4}{|c|}{ Types of Accommodation } \\
\hline & & Bed and Breakfasts & Small Hotel & Intermediate Hotel & Large Hotel \\
\hline & $\begin{array}{c}\text { Average built } \\
\text { year }\end{array}$ & 1982 & 1924 & 1962 & 1982 \\
\hline$A$ and $E$ & $\begin{array}{l}\text { Number of } \\
\text { floors }\end{array}$ & $<4$ & 4 & 10 & 26 \\
\hline B & Structural type & $\begin{array}{l}\text { Nonreinforced } \\
\text { masonry }\end{array}$ & $\begin{array}{l}\text { Reinforced } \\
\text { masonry }\end{array}$ & $\begin{array}{c}\text { Concrete } \\
\text { Concrete-masonry }\end{array}$ & $\begin{array}{c}\text { Concrete } \\
\text { steel-concrete }\end{array}$ \\
\hline $\mathrm{C}$ and $\mathrm{F}$ & $\begin{array}{l}\text { Geologic } \\
\text { conditions }\end{array}$ & Soft soil & Dense soil/Soft soil & Dense soil & Dense soil \\
\hline $\mathbf{D}$ & $\begin{array}{c}\text { Building } \\
\text { characteristics }\end{array}$ & $\begin{array}{c}\text { Collision, } \\
\text { deterioration, } \\
\text { horizontal and } \\
\text { vertical irregularities }\end{array}$ & $\begin{array}{l}\text { Collision, soft story, } \\
\text { vertical irregularity, } \\
\text { modification }\end{array}$ & $\begin{array}{l}\text { Vertical and } \\
\text { horizontal } \\
\text { irregularities, } \\
\text { collision }\end{array}$ & $\begin{array}{l}\text { Vertical and } \\
\text { horizontal } \\
\text { irregularities, } \\
\text { collision }\end{array}$ \\
\hline $\mathrm{E}$ & $\begin{array}{l}\text { Nonstructural } \\
\text { elements }\end{array}$ & Yes & Yes & No & No \\
\hline F1 & Frequentation & Low/Medium & Low/Medium & Important & Important \\
\hline F2 & $\begin{array}{l}\text { Accommodation } \\
\text { capacity }\end{array}$ & Low/Medium & Low/Medium & Medium/Important & Important \\
\hline \multicolumn{2}{|c|}{ Geographical sector } & 1 (principally) and 2 & 2 (principally) and 1 & 2 & 2 \\
\hline \multirow{2}{*}{\multicolumn{2}{|c|}{$\begin{array}{l}\text { Average Vulnerability Index Vi } \\
\text { Average level of vulnerability } \\
\text { Average Vi for all types }\end{array}$}} & $\begin{array}{c}32 \\
\text { Very high }\end{array}$ & $\begin{array}{c}27 \\
\text { High }\end{array}$ & $\begin{array}{c}14 \\
\text { Intermediate }\end{array}$ & $\begin{array}{c}9 \\
\text { Low }\end{array}$ \\
\hline & & \multicolumn{4}{|c|}{20 (Intermediate-High) } \\
\hline
\end{tabular}

The year of construction is a critical variable used as input for many of the criteria. The old city has the largest number of accommodations built before 1965, and the newest ones are located in the central part of the zone where a new urbanization plan is under progress (Figure 6). The latter are either concrete or steel buildings, which meet the latest seismic requirements from the building codes. These are typically intermediate to large-size hotels. Nevertheless, they often exhibit vertical and horizontal irregularities due to the constraints common in dense urbanized areas, which increases their vulnerability. Lodging houses and small hotels are mainly located in sector- 1 of the pilot zone. They are often the oldest buildings: 73\% were built before 1985 and a majority of them (61\%) are masonry buildings (i.e., $43 \%$ of the total). Among them, $72 \%$ and $11 \%$ have 10 to 300 rooms and more than 300 rooms, respectively. The number of tourists potentially impacted is estimated to vary from 300 to 10,000 depending on the time of year and the occupancy rate.

The map of Figure 7 illustrates the structural irregularities found in each investigated accommodation, which determine the score of criterion $\mathrm{D}$. One can notice that most buildings have from one up to seven irregularities listed in Table 5.

The map of Figure 8 shows the vulnerability index Vi for the selected accommodations. In total, the number of accommodations with low, intermediate, high, and very high vulnerability index are $29 \%, 25 \%, 13 \%$, and $33 \%$, respectively. The median value of $\mathrm{Vi}$ is 18 and the 94th confidence interval is from 5 to 53 . In the old city, 14 of the 18 analyzed buildings have a high or very high risk to be damaged (vulnerability index Vi between 20 and 30 or higher than 30 , respectively). That with the lowest value of Vi has been retrofitted recently. For the 51 buildings investigated in the Downtown area, over the 51 investigated buildings, 33\% have an intermediate risk and $43 \%$ have low risk. The highest values of $\mathrm{Vi}$ are highly correlated with areas where soil conditions are unfavorable (soil class D). This issue is especially critical in the old districts where the most recent NBCC codes were not yet implemented at the time of construction. 


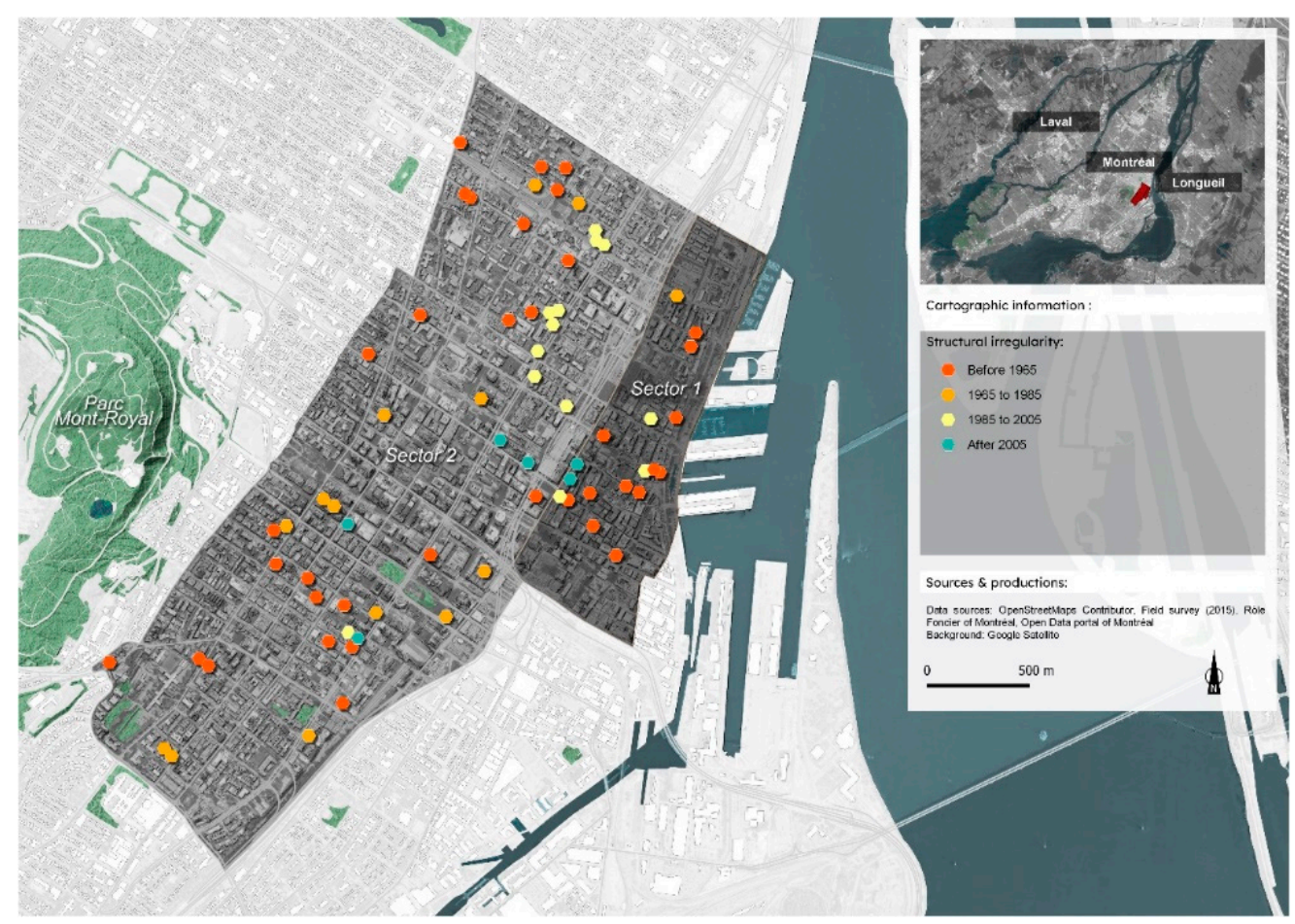

Figure 6. Distribution of the investigated buildings by period of construction: Hotels are divided into four groups of year of construction.

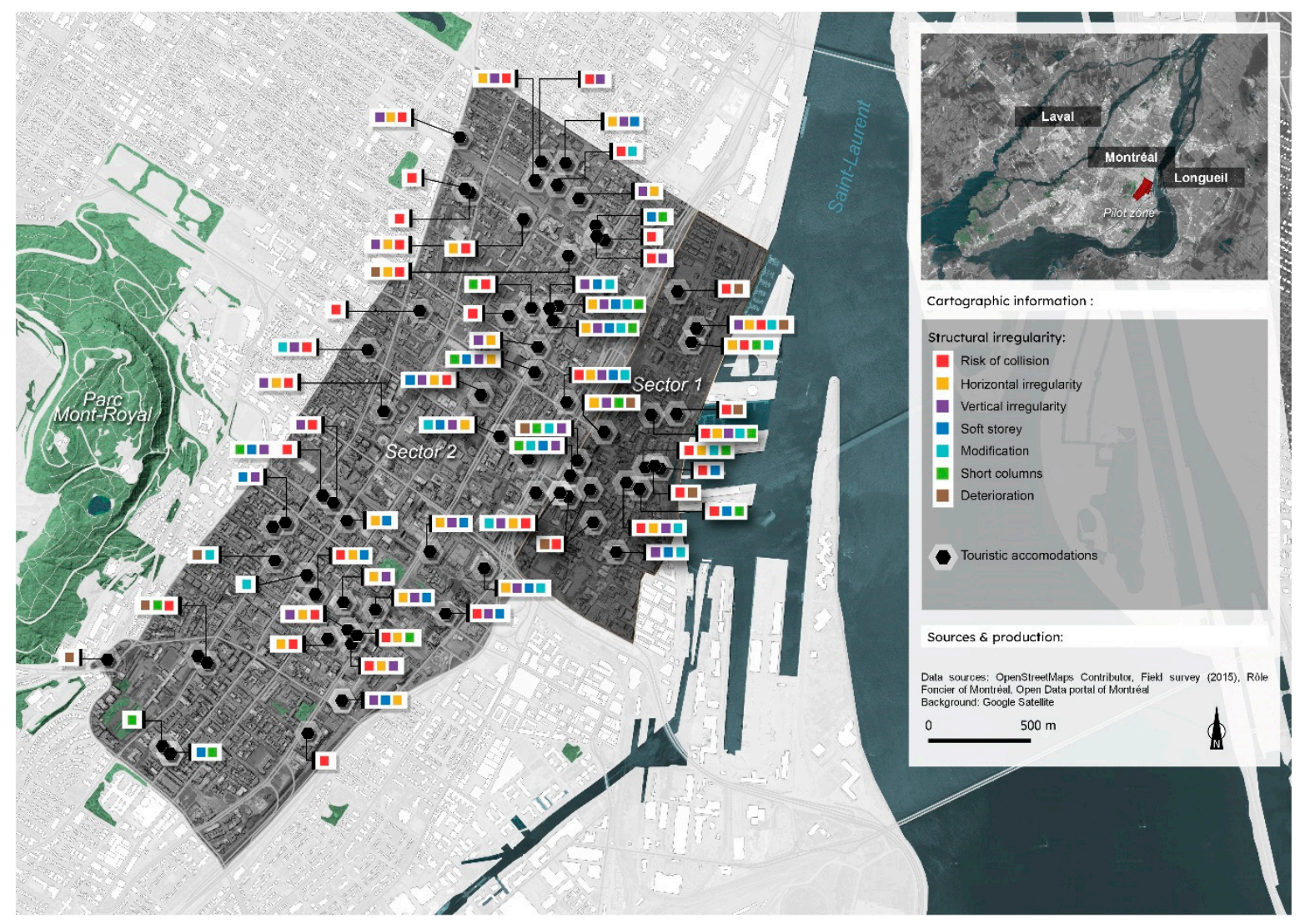

Figure 7. Structural irregularities for the selected buildings in the pilot zone. These parameters were used to calculate the score for criterion D defined in Table 5 . 


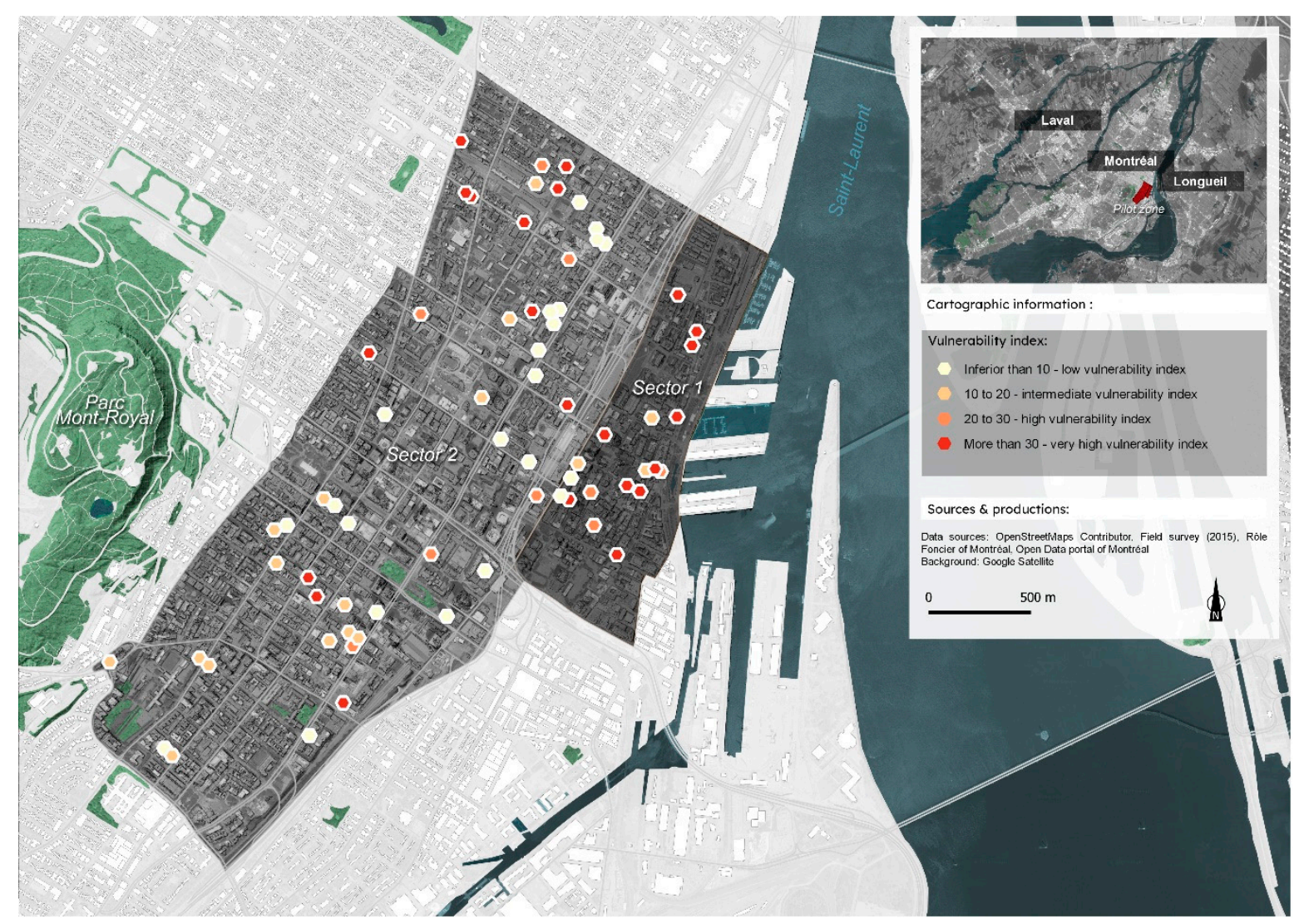

Figure 8. Vulnerability index of the selected buildings in the pilot zone.

\subsection{Correlation between Structural Vulnerability and the Preparedness Capacity}

The structural survey has been completed by a survey conducted among the general managers and employees in order to analyze their level of awareness and preparedness. Several questions are related to the hazard awareness, the level of preparedness, and the existence of an evacuation plan. The answers given by $45 \%$ of the panel were used to define a preparedness index.

Among the panelists, $9 \%$ have already experienced a seismic event abroad and very few were aware of past earthquakes that occurred in Quebec. Half of them considered that an earthquake is unlikely, which would reduce the prevention measures adopted by the management team.

The prevention and management of tourist accommodation against earthquakes gave varied results. For example, actions to reduce falling objects are taken by only $18 \%$ of the responders, while all provide emergency kits and reserves. In addition, $96 \%$ of the responders mentioned a fire evacuation plan and $40 \%$ have specific procedures for earthquake safety and evacuation. The survey also addresses the issue of training and simulations, adopted by $31 \%$ and $19 \%$ of the responders, respectively.

\section{Discussion}

A RVS was used to estimate the vulnerability of a representative sample of 70 tourist accommodations in Montreal using a scores matrix adapted from NBCC [15] and FEMA154 [13] procedures. The visual screening of buildings, complemented by an inspection of the satellite photos prior to the building visit, remains the most efficient approach for vulnerability assessments. The assessment of the structural characteristics is very dependent on the level of access allowed for each building and the information provided by owners or their representatives. All data collected for each investigated building were included in a GIS platform for further analysis and mapping. 
This study highlighted the potential issues with ageing tourist accommodation infrastructures. The oldest buildings in the city are mainly located in the Old Port, the historic heart of the city. These are predominantly $(40 \%)$ unreinforced masonry of adjoining brick walls that are vulnerable to strong ground motions [32]. The presence of soft soils in this sector was demonstrated as an aggravating factor in the case of strong ground motions. The downtown sector is a relatively dense urban landscape composed of buildings with more than 10 floors forming the skyline of Montreal. The resilience of tourist accommodations in this sector is greater than that in the old port sector.

The year of construction is a key factor in the calculation of the scores as it is related to the construction practices and standards. On average, the oldest hotels were built in the early twenties and the newest, less vulnerable buildings, large-size hotels, in the eighties.

The vulnerability assessment accounts for specific architectural and structural characteristics of the different building types. Structural irregularities were shown to play an important role as many modern buildings exhibit structural irregularities that increase vulnerability.

Soil-building interaction is another important factor that increases vulnerability when the resonance periods of the soil and the building coincide. At this stage, the scores given for selected periods of resonance for both buildings and soil in Table 5 are a preliminary approach, which may be improved by distributing the periods over the range of structures and region when further data are available.

Intermediate and large hotels have the highest economic value for initial cost of construction and economic activities (i.e., numbers of daily-accommodated persons). These are located in a sector with good soil conditions and have relatively low vulnerability indices (Table 9). On average, the oldest buildings are hostels built before 1982 and are principally located in the old port and have several structural irregularities (Figure 5). The small hotels have relatively high vulnerabilities mainly due to low building scores. In our sample, they are mainly found in sector 1 (33\% vs. $15 \%$ for sector 2$)$ but their presence is generalized across the island.

\section{Conclusions}

Our analysis of a representative set of accommodation buildings using an adapted RVS procedure has shown the general vulnerability of these buildings. In order to mitigate the impact of an earthquake on the city, buildings should be retrofitted in accordance with the building regulations [13] and the recent standard for seismic risk reduction of operational and functional components of buildings [37].

Several risk analyses have shown that Montreal may suffer important economic and structural losses in the case of a major earthquake [29,38-40]. These analyses do not include the effect on the touristic sector. The extension of our vulnerability analysis to a larger region and its incorporation in an impact analysis on economic activities following a major earthquake could provide incentives to improve the resilience of current facilities. In the meantime, the analysis of accessibility of damaged buildings with high vulnerability indices after a major event could be envisioned, as proposed in the preliminary work performed by Rodrigues [41] in Quebec City.

The proposed qualitative survey performed in Montreal could benefit from the recent advances in RVS [17] by including fuzzy logic models or multiple-criteria decision-making methods, as proposed recently by Harirchian et al. [42,43], for reinforced concrete buildings. These computational extensions of the field RVS aim to include the uncertainties in the collected data. Such improvements have shown to perform well compared to traditional RVS methods when using observed damage after an earthquake.

Finally, Brown et al. [44] developed an approach to evaluate disaster resilience mixing methods from predictors of economic, social, human, physical, natural, and cultural topics after the Kaikōura 2016 earthquake close to Wellington. These external parameters may also be considered when evaluating the vulnerability of public buildings such as the touristic accommodations. 
Author Contributions: Conceptualization, T.C. and P.R.; methodology and investigation, T.C.; validation, P.R. and L.C.; writing-original draft preparation, T.C. and P.R.; writing-review and editing, T.C., P.R. and L.C.; GIS mapping, T.C. All authors have read and agreed to the published version of the manuscript.

Funding: This research received no external funding.

Institutional Review Board Statement: Not applicable.

Informed Consent Statement: Not applicable.

Data Availability Statement: Information regarding the property value were extracted from the assessment role of Montreal in 2015 (https://montreal.ca/evaluation-fonciere). Other collected data are stored in a GIS platform and are available on request. Data used to produce the maps are from OSM-Open Street Map (http:/ / download.geofabrik.de/) and the city of Montreal https: / / donnees.montreal.ca/) in 2018. Collected data were first written on a paper sheet and then included in a Table. The collection of data took place in 2015 from February to April.

Acknowledgments: T.C. thanks the manager and the team of the selected hotels for their availability. The authors acknowledge the three reviewers for their fruitful comments and suggestions, which greatly improved the manuscript.

Conflicts of Interest: The authors declare no conflict of interest.

\section{Appendix A}

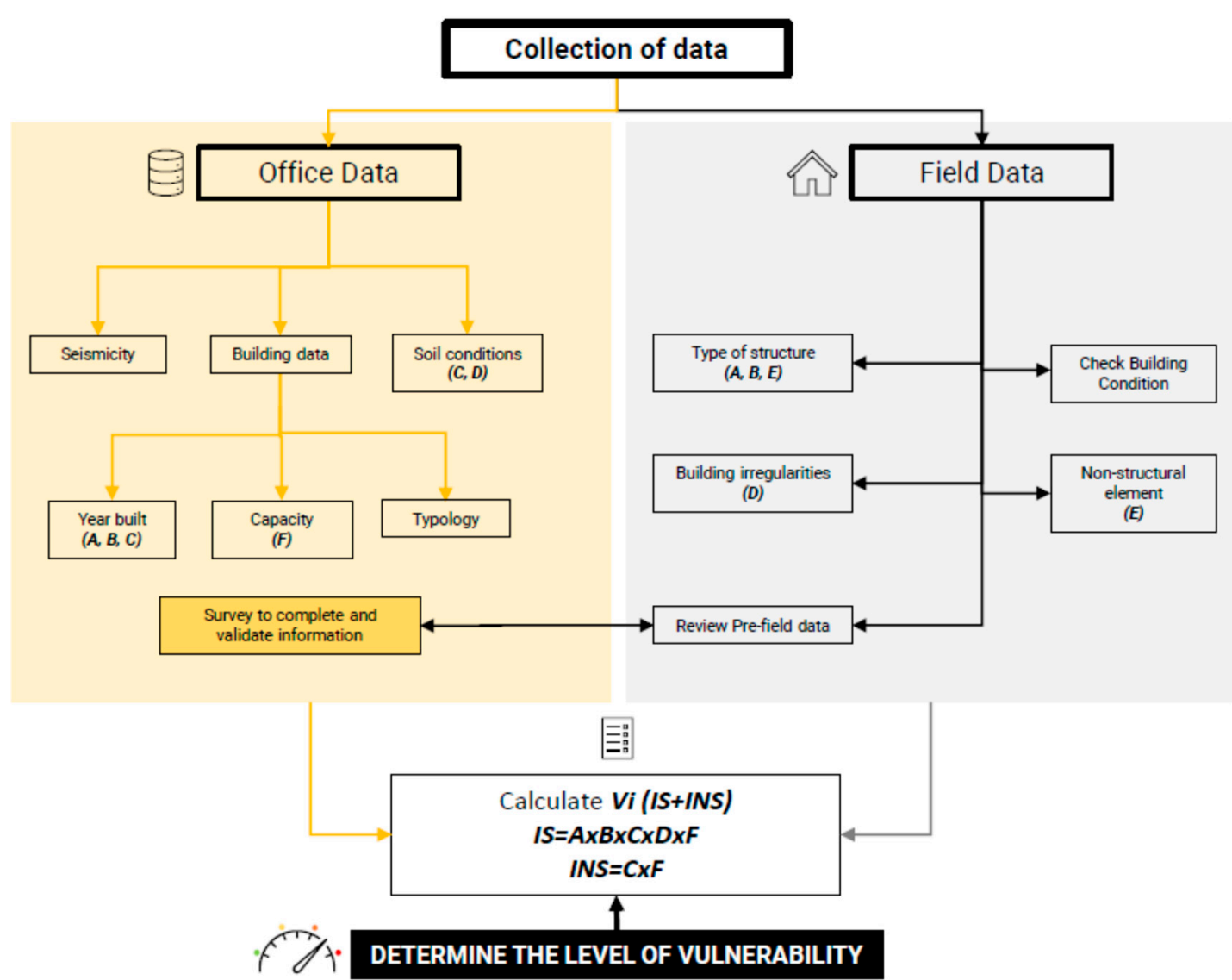

Figure A1. Flowchart of the RVs procedure used to analyze the vulnerability of accommodation buildings.

\section{References}

1. Mazzocchi, M.; Montini, A. Earthquake Effects on Tourism in Central Italy. Ann. Tour. Res. 2001, 28, 1031-1046. [CrossRef]

2. Yang, W.; Wang, D.; Chen, G. Reconstruction Strategies after the Wenchuan Earthquake in Sichuan, China. Tour. Manag. 2011, 32, 949-956. [CrossRef] 
3. Delamotte, G. L'économie Japonaise Après Fukushima. SciencesPo CERI CNRS 2012, 7.

4. Filimonau, V.; De Coteau, D. Tourism Resilience in the Context of Integrated Destination and Disaster Management (DM2). Int. J. Tour. Res. 2020, 22, 202-222. [CrossRef]

5. Tsai, C.-H.; Chen, C.-W. Development of a Mechanism for Typhoon-and Flood-Risk Assessment and Disaster Management in the Hotel Industry-A Case Study of the Hualien Area. Scand. J. Hosp. Tour. 2011, 11, 324-341. [CrossRef]

6. Mair, J.; Ritchie, B.W.; Walters, G. Towards a Research Agenda for Post-Disaster and Post-Crisis Recovery Strategies for Tourist Destinations: A Narrative Review. Curr. Issues Tour. 2016, 19, 1-26. [CrossRef]

7. Wilkinson, E.; Twigg, J.; Few, R. Building Back Better: A Resilience Caribbean after the 2017 Hurricanes; Overseas Development Institute (ODI): London, UK, 2018.

8. Mackay, E.A.; Spencer, A. The Future of Caribbean Tourism: Competition and Climate Change Implications. Worldw. Hosp. Tour. Themes 2017, 9, 44-59. [CrossRef]

9. Gross, M. After Maria's Devastation, Can Dominica Be a Destination Again. New York Times, 19 March $2018 ; 19$.

10. Orchiston, C.H. Tourism and Seismic Risk: Perceptions, Preparedness and Resilience in the Zone of the Alpine Fault, Southern Alps, New Zealand. Curr. Issues Tour. 2013, 16, 477-494. [CrossRef]

11. Dhellemmes, A. Vulnérabilité et Résilience du Secteur Touristique de San Francisco Face à un Séisme Majeur; Département de Géographie, Université de Paul-Valéry: Montpellier, France, 2014; Volume 3, p. 131.

12. Rosa, D. The Boxing Day Tsunami and Its Effects on Thailand's Tourism. 2012. Available online: http://www.neumann.edu/ academics/divisions/business/journal/review2012/rosa.pdf (accessed on 1 June 2016).

13. FEMA. Rapid Visual Screening of Buildings for Potential Seismic Hazards: A Handbook; FEMA: Washington, DC, USA, $2015 ;$ p. 388.

14. National Research Council of Canada. Construction Research Centre. Manual for Screening of Buildings for Seismic Investigation, Institute for Research in Construction; National Research Council Canada: Ottawa, OT, Canada, 1992; p. 107.

15. Canadian Commission on Building and Fire Codes. National Building Code of Canada: 2005; Canadian Commission on Building and Fire Codes National Research Council of Canada: Ottawa, ON, Canada, 2005.

16. Alam, N.; Alam, M.S.; Tesfamariam, S. Buildings' seismic vulnerability assessment methods: A comparative study. Nat. Hazards 2012, 62, 405-424. [CrossRef]

17. Harirchian, E.; Hosseini, S.E.A.; Jadhav, K.; Kumari, V.; Rasulzade, S.; Işık, E.; Wasif, M.; Lahmer, T. A review on application of soft computing techniques for the rapid visual safety evaluation and damage classification of existing buildings. J. Build. Eng. 2021, 43, 102536. [CrossRef]

18. Perrone, D.; O’Reilly, G.J.; Monteiro, R.; Filiatrault, A. Assessing seismic risk in typical italian school buildings: From in-situ survey to loss estimation. Int. J. Disaster Risk Reduct. 2020, 44, 101448. [CrossRef]

19. Tourism Montreal. 2019. Annual Report. Available online: https://toolkit.mtl.org/bynder/media/4977E233-0251-4345-8F64E9 CB5449D5DE/download?filename=2019-Annual-report\&extension=pdf (accessed on 1 June 2020).

20. Leblanc, G. A Closer Look at the 16 September 1732, Montreal Earthquake. Can. J. Earth Sci. 1981, 18, 539-550. [CrossRef]

21. Bent, A.L. Am Improved Source Mechanism for the 1935 Timiskaming, Quebec Earthquake from Regional Waveforms. Pure Appl. Geophys. 1996, 146, 5-20. [CrossRef]

22. Bent, A.L. Source Parameters of the Damaging Cornwall-Massena Earthquake of 1944 from Regional Waveforms. Bull. Seismol. Soc. Am. 1996, 86, 489-497.

23. Adams, J.; Basham, P. The Seismicity and Seismotectonics of Eastern Canada. Neotectonics N. Am. 1991, 1, $261-276$.

24. Adams, J.; Rogers, G.; Halchuk, S.; McCormack, D.; Cassidy, J. The Case for an Advanced National Earthquake Monitoring System for Canada's Cities at Risk. In Proceedings of the 7th US Conference on Earthquake Engineering, Boston, MA, USA, 21-25 July 2002; Volume 42, p. 10.

25. Rosset, P.; Bour-Belvaux, M.; Chouinard, L. Estimation and Comparison of Vs30; Microzonation Maps for Montreal Using Multiple Sources of Information. Bull. Earthq. Eng. 2015, 13, 2225-2239. [CrossRef]

26. Rosset, P.; Chouinard, L. Characterization of Site Effects in Montreal, Canada. Nat. Hazards 2009, 48, 295-308. [CrossRef]

27. Mitchell, D.; Tinawi, R.; Law, T. Damage Caused by the November 25, 1988, Saguenay Earthquake. Can. J. Civ. Eng. 1990, 17, 338-365. [CrossRef]

28. Ghofrani, H.; Atkinson, G.M.; Chouinard, L.; Rosset, P.; Tiampo, K.F. Scenario Shakemaps for Montreal. Can. J. Civ. Eng. 2015, 42, 463-476. [CrossRef]

29. Yu, K.; Chouinard, L.E.; Rosset, P. Seismic Vulnerability Assessment for Montreal. Georisk Assess. Manag. Risk Eng. Syst. Geohazards 2016, 10, 164-178. [CrossRef]

30. Rosset, P.; Kert, M.; Youance, S.; Nollet, M.-J.; Chouinard, L. Could Montreal Residential Buildings Suffer Important Losses in Case of Major Earthquakes? In Proceedings of the 12th Canadian Conference on Earthquake Engineering, Quebec, QC, Canada, 17-20 June 2019; p. 7.

31. Chouinard, L.; Rosset, P. On the Use of Single Station Ambient Noise Techniques for Microzonation Purposes: The Case of Montreal. In Shear Wave Velocity Measurement Guidelines for Canadian Seismic Site Characterization in Soil and Rock. Open File 7078; Hunter, J.A., Crow, H.L., Eds.; Geological Survey of Canada: Ottawa, ON, Canada, 2012; pp. 85-93.

32. Lefebvre, K. Caractérisation Structurale et Évaluation de La Vulnérabilité Sismique Des Bâtiments Historiques En Maçonnerie Du Vieux-Montréal. Master' s Thesis, École de technologie supérieure, Montréal, QC, Canada, 2004; p. 230. 
33. Uma, S.; Dhakal, R.P.; Nayyerloo, M. Vulnerability Assessment of Christchurch Buildings in Canterbury Earthquakes; GNS Science: Lower Hutt, New Zealand, 2013; ISBN 1-972192-55-8.

34. Zacek, M. Construire Parasismique: Risque Sismique, Conception Parasismique Des Bâtiments; Ed. Parenthèses: Marseille, France, 1996; ISBN 2-86364-054-2.

35. Mitchell, D.; Paultre, P.; Tinawi, R.; Saatcioglu, M.; Tremblay, R.; Elwood, K.; Adams, J.; DeVall, R. Evolution of Seismic Design Provisions in the National Building Code of Canada. Can. J. Civ. Eng. 2010, 37, 1157-1170. [CrossRef]

36. Chouinard, L.; Rosset, P. Microzonation of Montreal, Variability in Soil Classification. In Proceedings of the 4th IASPEI/IAEE International Symposium, Santa Barbara, CA, USA, 23-26 August 2011; p. 5.

37. Canadian Standards Association. Seismic Risk Reduction of Operational and Functional Components (OFCs) of Buildings; CSA Group: Toronto, ON, Canada, 2017; p. 134.

38. Air Worldwide. Study of Impact and the Insurance and Economic Cost of Major Earthquakes in British Columbia and Ontario/Québec; Insurance Bureau of Canada: Boston, MA, USA, 2013; p. 264.

39. Rosset, P.; Kert, M.; Youance, S.; Nollet, M.-J.; Chouinard, L. The Use of HAZCAN to Assess the Earthquake Risk of Residential Buildings in Montreal, Canada. In Proceedings of the Conference of the Canadian Society of Civil Engineering, Laval, QC, Canada, 12-15 June 2019; p. 4.

40. SwissRe Le Risque Sismique Dans l’Est Canadien. Gare Aux Secousses; Swiss Re Institute: Zurich, Switzerland, 2017 ; p. 16.

41. Rodrigues, C. Vulnérabilité de l'accessibilité de La Ville de Québec Face à l'aléa Sismique: Du Diagnostic Territorial à La Gestion de Crise; Département de Géographie, Université de Paul-Valéry: Montpellier, France, 2017; Volume 3, p. 134.

42. Harirchian, E.; Lahmer, T. Developing a Hierarchical Type-2 Fuzzy Logic Model to Improve Rapid Evaluation of Earthquake Hazard Safety of Existing Buildings. Structures 2020, 28, 1384-1399. [CrossRef]

43. Harirchian, E.; Jadhav, K.; Kifaytullah, M.; Ehsan, S.; Hosseini, A.; Lahmer, T. A Comparative Study of Mcdm Methods Integrated with Rapid Visual Seismic Vulnerability Assessment of Existing Rc Structures. Appl. Sci. 2020, 28, 1384. [CrossRef]

44. Brown, N.A.; Rovins, J.E.; Orchiston, C.; Feldmann-Jensen, S.; Johnston, D. Disaster Resilience in Wellington's Hotel Sector: Research Update and Summary. Aust. J. Disaster Trauma Stud. 2019, 23, 77-81. 